\title{
A maximum power point tracking based on levy flight optimization
}

\author{
C. Charin', Dahaman Ishak ${ }^{2}$, Muhammad Ammirrul Atiqi Mohd Zainuri ${ }^{3}$ \\ ${ }^{1,2}$ School of Electrical and Electronics Engineering, Universiti Sains Malaysia, Malaysia \\ ${ }^{1}$ Faculty of Engineering Technology, Universiti Malaysia Perlis, Malaysia \\ ${ }^{3}$ Faculty of Engineering and Built Environment, Universiti Kebangsaan Malaysia, Malaysia
}

\begin{tabular}{l} 
Article Info \\
\hline Article history: \\
Received Feb 4, 2020 \\
Revised Mar 6, 2020 \\
Accepted Apr 15, 2020 \\
\hline Keywords: \\
Global maximum power point \\
Levy flight optimization \\
Maximum power point tracking \\
Partial shading condition
\end{tabular}

Partial shading condition

\begin{abstract}
This paper proposes a Levy flight global maximum power point tracking for solar photovoltaic (PV) system under partial shading conditions. The proposed method comes with merits such as simplicity, fast response and free of oscillation. This algorithm uses random search over the exploration space and compares the previous and current states to obtain the best solution. For evaluation and comparative analysis, performance of the proposed method is also measured against Perturb and Observe (P\&O) and Particle Swarm Optimization (PSO). All three algorithms are simulated in MATLAB/Simulink environment. Simulation results are satisfactory over the conducted tests under uniform and non-uniform irradiance. The proposed algorithm is able to track global maximum power point (GMPP) under partial shading conditions with fast tracking time and zero ripple at steady-state.
\end{abstract}

This is an open access article under the CC BY-SA license.

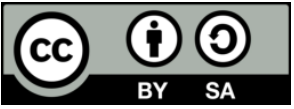

\section{Corresponding Author:}

Dahaman Ishak,

School of Electrical and Electronic Engineering,

Universiti Sains Malaysia, Engineering Campus,

14300 Nibong Tebal, Penang, Malaysia.

Email: dahaman@usm.my

\section{INTRODUCTION}

Renewable energy is seen as a promising alternative in generating electrical power [1]. Solar is one of the potential candidates in power generation due to availability of the sun [2] and cleanliness [3]. Moreover, the operational and maintenance costs of solar photovoltaic (PV) are low compared to other renewable energy resources [4]. This emerging technology has gained a lot of interests from researchers in the area of grid integration, control and optimization [5]. However, this technology is still limited to its efficiency [6]. Efficiency of PV system is still low, less than 22.4\% [3,7]. Additionally, non-linear parameters such as temperature and irradiance affect characteristics of current and voltage curves of the solar PV [1]. Thus, maximum power point tracking (MPPT) controllers are needed for harnessing the optimum power from PV modules [8]. Various MPPT methods have been proposed to obtain optimum power from solar PV. For instance, two MPPT methods are popularly used such as Perturbation and Observation (P\&O) [9] and Incremental Conductance (IncCond) [10,11]. These methods work well under uniform irradiance. However, they faced some constraints under non-uniform irradiances across PV modules [12]. These conventional MPPT algorithms fail to distinguish in between global and local maxima, causimg the system to be trapped at local maxima power point [13].

Practically, connected PV arrays can be affected by environmental changes such as cloud, leaves and dust [14,15]. This phenomenon is inevitable and unpredictable which cause partial shading condition (PSC) to occur [16]. Soft computing methods are considered as the most potential candidates to mitigate the 
concern of non-uniform irradiance [17]. Nowadays, soft computing methods such as artificial intelligent network (ANN) [15,16], Fuzzy Logic Control (FLC) [16,18,19] and Particle Swarm Optimization (PSO) are most preferable among researchers [22]. PSO algorithm is one of the most leading MPPT techniques used to detect global maximum power point (GMPP) under PSC [2]. This method comes with great advantages due to its good performance, simplicity, easy to implement and less complex mathematical structure [16]. Conventional PSO algorithm works well under PSC. However, due to large searching area, this method suffers longer computational time [16] and steady-state oscillation. In addition, this algorithm also suffers from intermittent tracking since its requires an appropriate initial value to be able to detect certain changes of irradiance condition [23]. To solve the aforementioned problems, a Levy flight algorithm is proposed. The main feature of the proposed method is the absence of oscillation at steady-state condition, no specific initial value is required and fast computing time. This algorithm comes with ability to track extreme environmental condition such as PSC. Compared to other conventional techniques, Levy flight algorithm has fast tracking speed and is simple to be implemented. The rest of this paper is organized as follows. Section 2 presents on PSC. Section 3 introduces the theoretical framework of Levy flight optimization. Section 4 discusses the simulation results. Finally, conclusion is given in Section 5.

\section{PARTIAL SHADING CONDITIONS}

Typically under PSC, different photon current, $\mathrm{I}_{\mathrm{ph}}$ is generated in conjunction with different irradiances penetrated at PV array. This phenomenon indirectly generates a hot spot in the shaded modules and might damage the modules. The solution to this aforementioned problem is done by introducing bypass diode which is connected in parallel to each module. The presence of bypass diode in each module creates multiple peaks of P-V and I-V curves as shown in Figure 1 [6].

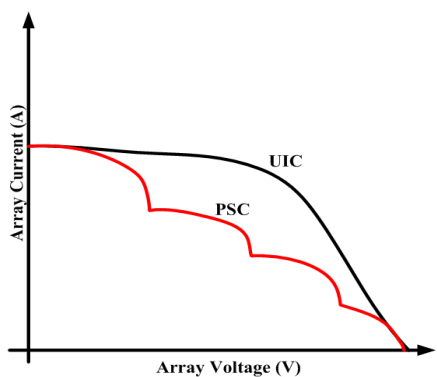

(a)

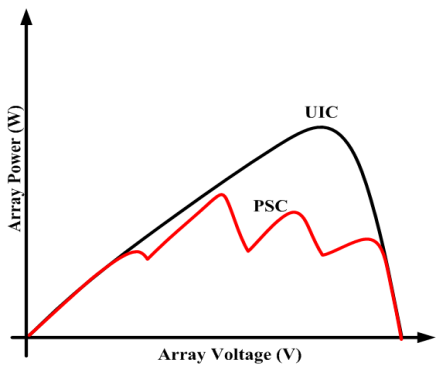

(b)

Figure 1. (a) P-V and (b) I-V curves under uniform condition (UIC) and PSC

PV module BPSX150 with specifications as shown in Table 1 is used to generate the pattern of partial shading conditions in this paper. The specifications are obtained under standard test condition (STC). There are three different patterns of partial shading conditions generated as shown in Table 2. The same patterns are generated in MATLAB/Simulink for four PV modules BPSX150 connected in series under partial shading condition.

Table 1. Specifications of photovoltaic module

\begin{tabular}{cc} 
BPSX150 & \\
\hline Parameters & Rating \\
\hline STC power rating, Pmax & $150 \mathrm{~W}$ \\
Open circuit voltage, Voc & $43.5 \mathrm{~V}$ \\
Short circuit current, Isc & $4.75 \mathrm{~A}$ \\
Voltage at maximum power, Vmpp & $34.5 \mathrm{~V}$ \\
Current at maximum power, Impp & $4.35 \mathrm{~A}$ \\
Number of cells & 72 \\
\hline
\end{tabular}

Table 2. Partial shading profile

\begin{tabular}{llllll}
\hline Cases & Patterns $(\mathrm{W} / \mathrm{m} 2)$ & \multicolumn{2}{c}{ Peak power $(\mathrm{W})$} & & \\
& & Peak 1 & Peak 2 & Peak 3 & Peak 4 \\
\hline PSC1 & $1000,800,400,200$ & 138.94 & 249.37 & 205.86 & 142.22 \\
PSC2 & $400,400,1000,200$ & 138.21 & & 131.26 & 133.56 \\
PSC3 & $1000,400,200,600$ & 138.21 & 192.86 & 203.59 & 141.54 \\
\hline
\end{tabular}

\section{LEVY FLIGHT OPTIMIZATION}

Paul Levy is a French mathematician who introduced Levy flight distribution in 1937 [24]. Levy flight is considered as a breakthrough over traditional Brownian motion by considering distribution for 
current and next jump using same mathematical form. Levy motion is diverged in motion. Nowadays, this motion is being widely explored in nature since Levy distribution can be applied in the most of analyses such as in physics, biology, finance and economics. The behavior of animal searching for food is being observed. It is noticed that the animal behavior looking for food is classified as random or quasi-random manner. The decision of animal in next move for food search is based on current position and transition probability. Thus, this behavior can be modeled mathematically. It is observed that most animal and insects exhibit Levy flight behavior. Subsequently, this behavior is applied in optimization and optimal search. Power law is used to mathematically model the distribution of Levy flight [24]. Random walk in Levy distribution is comprised of length, $l$ drawn from power law function as in (1) $[24,25]$.

$$
\mathrm{p}(l)=l^{-\beta}
$$

where $l$ denotes by flight length and $\beta$ is variance, $1<\beta<3$.

A simplified Levy flight is expressed in (2).

$\mathrm{x}^{\mathrm{t}+1}=\mathrm{x}^{\mathrm{t}}+\alpha \otimes \operatorname{Levy}$

In here, $\mathrm{x}^{\mathrm{t}+1}$ is the next state, $\mathrm{x}^{\mathrm{t}}$ is current state, $\alpha$ is step size and $\otimes$ is product of entrywise multiplications.

A simplified step size, s sample generation is expressed in (3).

$$
\mathrm{s}=\alpha \otimes \operatorname{Levy}(\beta)=\mathrm{kx}\left(\frac{u}{|v|^{\frac{1}{\beta}}}\right)\left(v_{\text {best }}-v_{i}\right)
$$

where $\mathrm{k}$ denotes as Levy multiplying coefficient, $\beta$ is 1.5 , while $\mathrm{u}$ and $\mathrm{v}$ are from normal distribution. Given the term $u$ is expressed in (4).

$\mathrm{u} \approx \mathrm{N}\left(0, \sigma_{\mathrm{u}}^{2}\right)$

While $\sigma_{\mathrm{u}}$ is expressed in (5).

$$
\sigma_{u}=\left\{\frac{\Gamma(1+\beta) \sin \left(\frac{\pi \beta}{2}\right)}{\Gamma\left(\frac{1+\beta}{2}\right) \beta 2^{\frac{(\beta-1)}{2}}}\right\}^{\frac{1}{\beta}}
$$

Given equation $v$ is denoted by expression (6).

$\mathrm{v}=\mathrm{N}\left(0, \sigma_{\mathrm{v}}^{2}\right)$

While $\sigma_{v}$ is expressed in (7).

$\sigma_{v}=1$

Figure 2(a) shows the flowchart of Levy flight optimization (LFO). In this algorithm, a set of particles is chosen. One best-known location is selected as starting. A whole new generation is produced with Levy flight motion with random distribution. The new generation is evaluated with best-known location. This process is continuously executed until one promising point is obtained which is the best solution.

\subsection{Mechanism of the proposed MPPT search}

Initially, all the particles are distributed entirely at P-V curve. Four particles, D are selected in this proposed algorithm. Figure 2 shows the flowchart of the movement mechanism of the particles. The selected particles are initially distributed at duty cycle $0.1,0.2,0.5$ and 0.7 respectively. The power at the respective duty cycle is recorded. Based on the initial distribution of the particles, the highest power is selected. The selected particle with the highest power is the initial best particle. This particle serves as the guidance for all other particles for their next movement. The direction and velocity of the movement of the particle is guided by Levy flight as shown in (2). The step size of the particle is random as the particle moves closer to the MPP the step size is smaller. The step size becomes zero once all the particles assigned moved towards MPP. The particles continue to update their search until the new best particle is found. Once new best particle found, 
new best particle is updated. The next iteration is excecuted until the best solution is found. The best solution is the output $\mathrm{D}$. At this condition, the maximum power is successfully tracked by the algorithm.

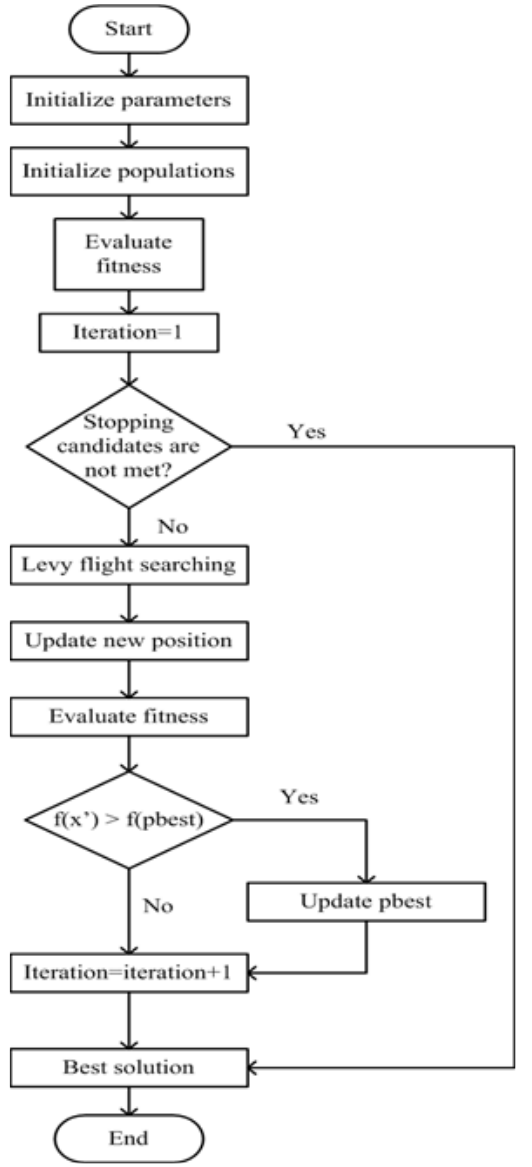

(a)

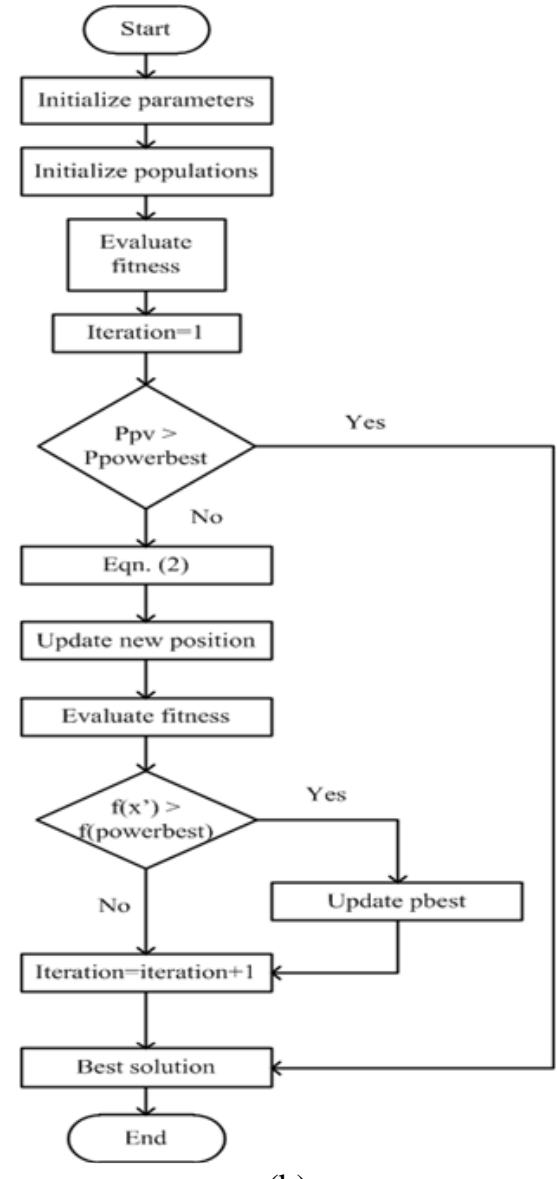

(b)

Figure 2. (a) Levy flight optimization (b) Levy flight GMPP

\subsection{Implementation of the proposed MPPT}

The same basic idea of LFO as discussed previously is applied to track maximum power point of PV module. A flowchart of LFO GMPP is as shown in Figure 2(b). A full PV system is shown in Figure 3. In here, this algorithm is functioned to extract global maximum power by comparing with the existing power points and identifying photovoltaic power which is needed to regulate the duty cycle of the boost converter. Levy flight algorithm is applied in solar power system to trace global maximum power point under partial shading conditions. The main program starts by sensing the voltage and current of PV module as shown in the flowchart of Figure 2(b). Each duty cycle is randomly distributed within the searching space. The fitness of each duty cycle is evaluated and the best duty cycle, pbest is found. Then, for each duty cycle position is updated based on random probability. The position of duty cycle is updated based on (2). If the current duty cycle is more than current pbest, then current duty cycle becomes pbest. By employing Levy flight in global power search, it enhances the search capability to perform global exploration throughout the searching space. In Levy flight, the main key factor in the search is determined by $\beta$ parameter. In here, $\beta$ value of 1.5 is chosen. 


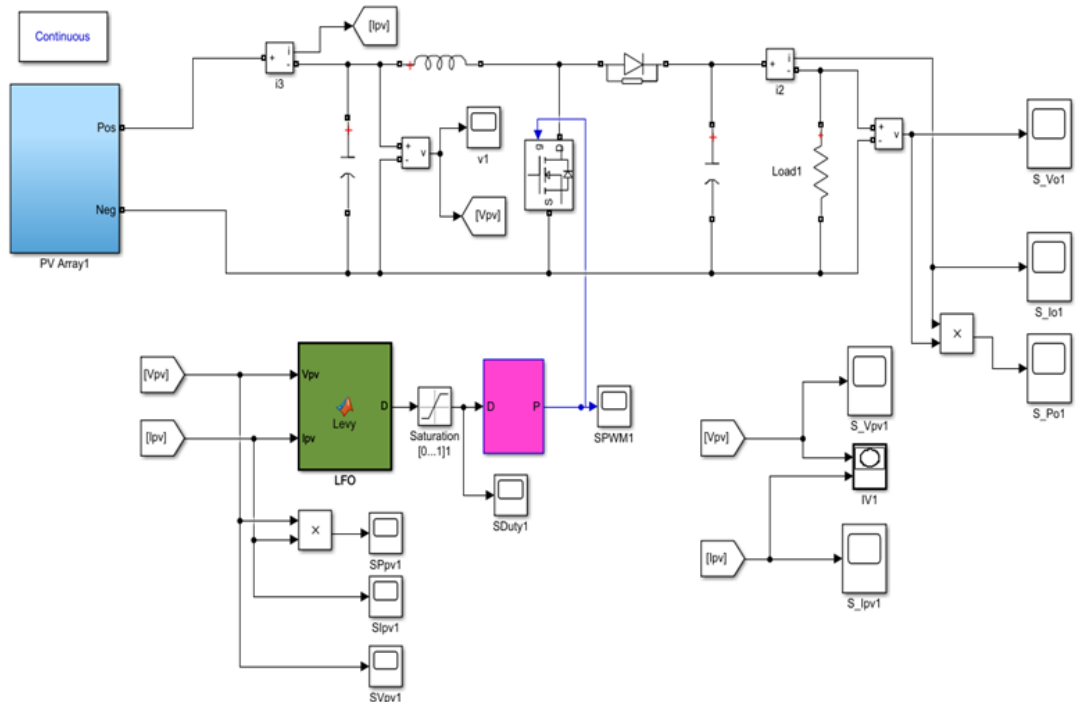

Figure 3. Solar PV power system

\section{SIMULATION RESULTS}

In this study, a solar power system is modeled in MATLAB/Simulink to verify the effectiveness of the proposed algorithm as depicted in Figure 3. It shows a dc supply system powered by PV as input source connected to a boost converter and dc load. In this simulation, the PV model is represented as a current source parallel with a single diode, a parallel shunt resistor and a series resistor. Boost converter having parameter specifications of inductor with value of $100 \mathrm{uH}$, output capacitor with value of $100 \mathrm{uF}$ and $20 \mathrm{kHz}$ of switching frequency is designed and modeled in MATLAB/Simulink. The boost converter is controlled by a power MOSFET. PWM switching is varied based on duty cycle. A constant load of $32 \Omega$ is applied. The duty cycle is adjusted by the proposed algorithm to get global maximum power point. Firstly, the proposed algorithm is tested under uniform irradiance and later under non-uniform irradiances. Figure 4 shows results of PV power, voltage and current under varying irradiances.

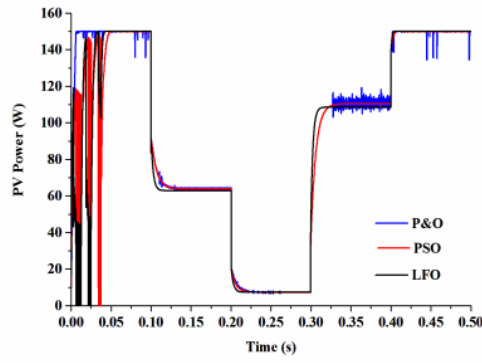

(a)

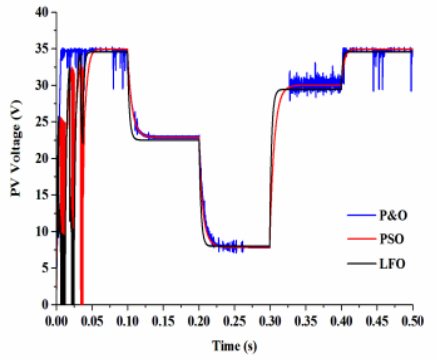

(b)

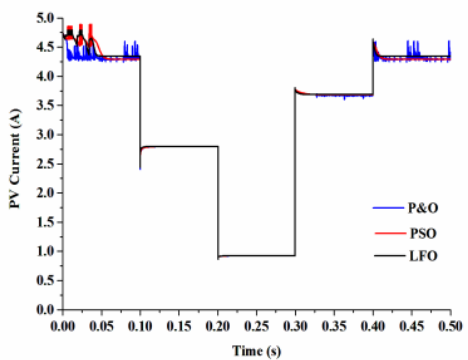

(c)

Figure 4. Photovoltaic under varying irradiances (a) power (b) voltage (c) current 
Based on the results, all algorithms are able to track maximum power point under changing irradiances. However, $\mathrm{P} \& \mathrm{O}$ algorithm suffers from losses at certain irradiance. The oscillations occur at certain irradiance contributed to power losses. As can be seen, $\mathrm{P} \& \mathrm{O}$ algorithm has oscillation, slower time response and unstable. PSO algorithm shows low oscillation, fast respond time and stable. However, the proposed LFO shows the best performance as compared to both P\&O and PSO since LFO has the lowest oscillation, fastest respond time and the most stable.

Next, the performance of the algorithm is tested under partial shading conditions. Three different patterns of partial shading conditions with different irradiances are penetrated at four series PV modules. It is well known that $\mathrm{P} \& \mathrm{O}$ algorithm has tendency to trap at local maxima during its search. Thus, this algorithm may fail to detect global maxima under partial shading conditions. Figure 5 shows simulation results for PSO and LFO algorithms. It can clearly be observed that both algorithms are able to detect global maximum power point. In terms of oscillation, both have low steady state oscillation. Further analysis is done in terms of respond time, it shows that LFO has faster tracking time compared to PSO, and both algorithms are stable.

Partial shading condition 2 is tested where maximum power of each peak is closed to each other. The test is performed to assess the intelligence of both algorithms in distinguishing between very closely peaks to each other. Figure 6 shows simulation results under PSC 2 for power, voltage and current. Based on these simulation results, both algorithms are able to distinguish global maximum power peak even though the peaks are closed to one another. Both algorithms also produce low steady-state oscillation and stable. In terms of respond time, it shows that LFO has faster respond time compared to PSO.

Similarly, the test is repeated for PSC 3. In this condition, the global peak is at the right side of the P-V curve. Both algorithms are tested under this condition. Based on results shown in Figure 7, PSO algorithm can detect the global maximum power point with some changes on the initial value of duty cycle being made. However, for LFO, the same initial values are used and this algorithm is able to detect global maximum power point. Both have low steady-state oscillation. However, in terms of respond time, LFO has faster respond time compared with PSO, and both algorithms yield stable results. Table 4 provides a comparison between conventional P\&O, PSO and LFO methods in terms of oscillation, respond time and stability.

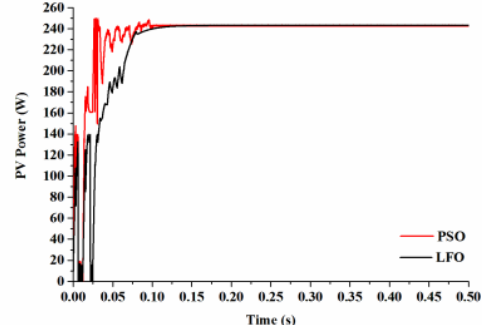

(a)

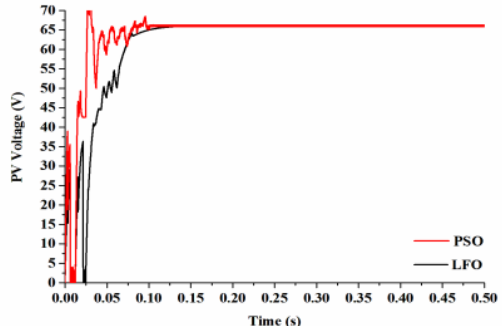

(b)

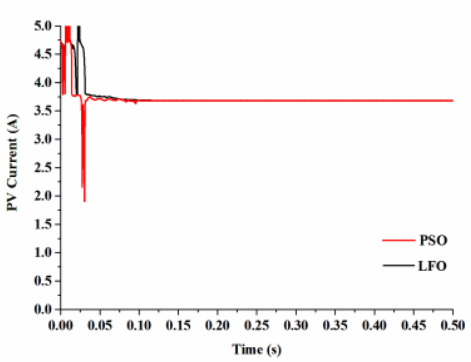

(c)

Figure 5. Partial shading condition 1 (a) power (b) voltage (c) current waveforms 


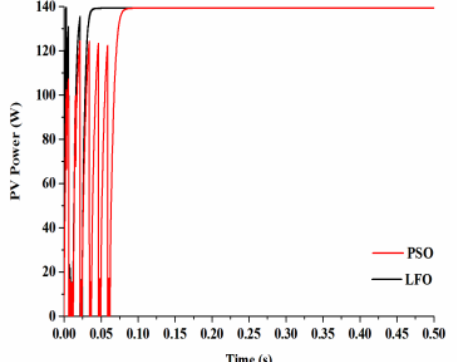

(a)

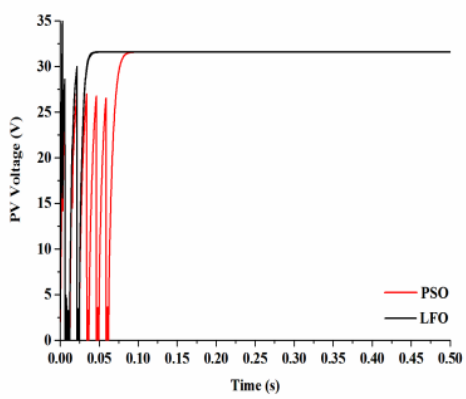

(b)

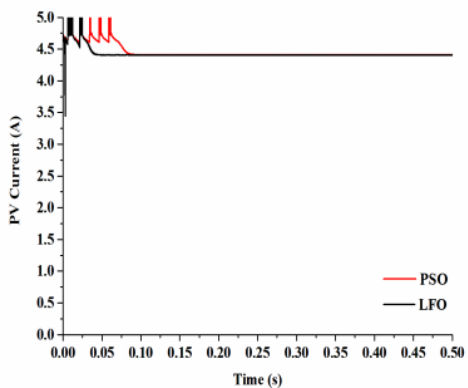

(c)

Figure 6. Partial shading condition 2 (a) power (b) voltage (c) current waveforms

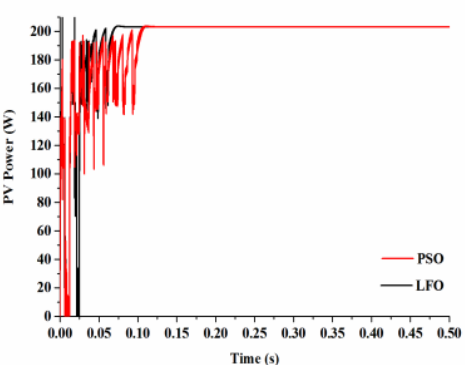

(a)

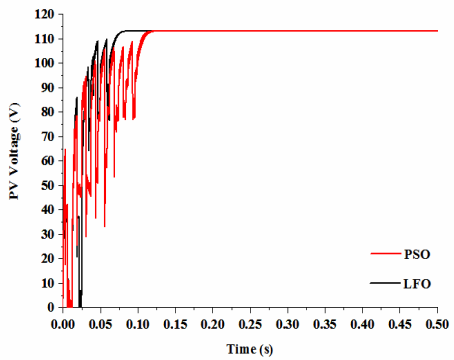

(b)

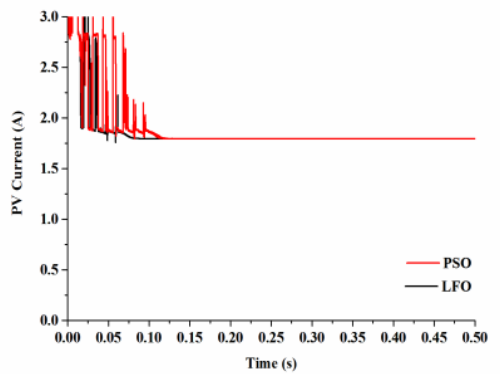

(c)

Figure 7. Partial shading condition 3 (a) power (b) voltage (c) current waveforms

Table 4. Comparison of P\&O, PSO and LFO under PSCs

\begin{tabular}{cccc}
\hline Algorithms & Oscillation & Respond Time & Stability \\
\hline P\&O & Fail & Fail & Fail \\
PSO & Low & Vary & Vary \\
LFO & Low & Fast & Stable \\
\hline
\end{tabular}




\section{CONCLUSION}

In this paper, LFO algorithm has been proposed. In this algorithm, the search was randomly executed in between the searching space, and no specific initial value was required. In this study, a standalone PV system with boost converter was modeled in MATLAB/Simulink to verify the effectiveness and the performance of the algorithm. In here, the proposed algorithm was tested under two test conditions which were under uniform and non-uniform irradiances. The algorithm was compared with conventional $\mathrm{P} \& \mathrm{O}$ and PSO. Further studies were carried out under non-uniform conditions with three different patterns of PSC. Based on the results, it can be noted that LFO algorithm is able to work well under uniform and nonuniform irradiances. In addition, this algorithm has low oscillation, fast respond time and stable. It is expected in future work, this algorithm will be deployed in the hardware and experiment to further validate its performance and effectiveness.

\section{ACKNOWLEDGEMENTS}

The authors would like to thank Universiti Sains Malaysia for the financial support under RUI grant scheme with project number 1001/PELECT/8014027.

\section{REFERENCES}

[1] M. A. G. De Brito, L. Galotto, L. P. Sampaio, G. De Azevedo Melo, and C. A. Canesin, "Evaluation of the main MPPT techniques for photovoltaic applications," IEEE Trans. Ind. Electron., vol. 60, no. 3, pp. 1156-1167, 2013.

[2] C. Manickam, G. R. Raman, G. P. Raman, S. I. Ganesan, and C. Nagamani, "A Hybrid Algorithm for Tracking of Global MPP based on Perturb and Observe and Particle Swarm Optimization with Reduced Power Oscillation in String Inverters," IEEE Trans. Ind. Electron., vol. 0046, no. c, pp. 1-1, 2016.

[3] H. Islam et al., "Performance Evaluation of Maximum Power Point Tracking Approaches and Photovoltaic Systems," Energies, vol. 11, no. 2, p. 365, 2018.

[4] S. Hajighorbani, S.; Radzi, M.A.M.; Kadir, M.Z.A.A.; Shafie, "Dual Search Maximum Power Point (DSMPP) Algorithm Based on Mathematical Analysis under Shaded Conditions," Energies, pp. 12116-12146, 2015.

[5] I. Alhamrouni, M. K. Rahmat, F. A. Ismail, M. Salem, A. Jusoh, and T. Sutikno, "Design and development of SEPIC DC-DC boost converter for photovoltaic application," ," International Journal of Power Electronics and Drive Systems (IJPEDS), vol. 10, no. 1, p. 406, 2019.

[6] K. Saidi, M. Maamoun, and M. Bounekhla, "A new high performance variable step size perturb-and-observe MPPT algorithm for photovoltaic system,", , International Journal of Power Electronics and Drive Systems (IJPEDS), vol. 10, no. 3, pp. 1662-1674, 2019.

[7] O. Lagdani et al., "PV array connected to the grid with the implementation of MPPT algorithms ( INC, P \& O and FL method )," , "International Journal of Power Electronics and Drive Systems (IJPEDS), vol. 10, no. 4, pp. 2084 2095, 2019.

[8] M. Killi and S. Samanta, "Modified perturb and observe MPPT algorithm for drift avoidance in photovoltaic systems," IEEE Trans. Ind. Electron., vol. 62, no. 9, pp. 5549-5559, 2015.

[9] M. R. Bengourina, M. Rahli, S. Slami, and L. Hassaine, "PSO based direct power control for a multifunctional grid connected photovoltaic system," ," International Journal of Power Electronics and Drive Systems (IJPEDS), vol. 9, no. 2, pp. 610-621, 2018.

[10] M. Slimi, A. Boucheta, and B. Bouchiba, "Maximum power control for photovoltaic system using intelligent strategies," International Journal of Power Electronics and Drive Systems (IJPEDS), vol. 10, no. 1, p. 423, 2019.

[11] S. Farajdadian and S. M. H. Hosseini, "ScienceDirect Optimization of fuzzy-based MPPT controller via metaheuristic techniques for stand-alone PV systems," Int. J. Hydrogen Energy, vol. 44, no. 47, pp. 25457-25472, 2019.

[12] A. Kihal, F. Krim, A. Laib, B. Talbi, and H. Afghoul, "An improved MPPT scheme employing adaptive integral derivative sliding mode control for photovoltaic systems under fast irradiation changes," ISA Trans., vol. 87, pp. 297-306, 2019.

[13] H. Otmane, M. Youssef, B. Mokhtar, and A. Info, "Comparative analysis of cascaded Fuzzy-PI controllers basedMPPT and perturb and observe MPPT in a grid-connected PV system operating under different weather and loading conditions,", International Journal of Power Electronics and Drive Systems (IJPEDS), vol. 10, no. 4, pp. 1986-1994, 2019.

[14] D. Sera, L. Mathe, T. Kerekes, S. V. Spataru, and R. Teodorescu, "On the perturb-and-observe and incremental conductance mppt methods for PV systems," IEEE J. Photovoltaics, vol. 3, no. 3, pp. 1070-1078, 2013.

[15] H. Rezk et al., "A novel statistical performance evaluation of most modern optimization-based global MPPT techniques for partially shaded PV system," Renew. Sustain. Energy Rev., vol. 115, no. September, p. 109372, 2019.

[16] M. Alshareef, Z. Lin, M. Ma, and W. Cao, “Accelerated Particle Swarm Optimization for Photovoltaic Maximum Power Point Tracking under Partial Shading Conditions," Energies, vol. 12, no. 4, p. 623, 2019. 
[17] N. Hashim, Z. Salam, D. Johari, and N. F. Nik Ismail, "DC-DC Boost Converter Design for Fast and Accurate MPPT Algorithms in Stand-Alone Photovoltaic System," International Journal of Power Electronics and Drive Systems (IJPEDS), vol. 9, no. 3, p. 1038, 2018.

[18] H. A. Attia and F. D. Gonzalo, "Stand-alone PV system with MPPT function based on fuzzy logic control for remote building applications," International Journal of Power Electronics and Drive Systems (IJPEDS), vol. 10, no. 2, p. 842, 2019.

[19] S. Della Krachai, A. B. Stambouli, M. Della Krachai, M. Bekhti, and A. Info, "Experimental investigation of artificial intelligence applied in MPPT techniques," ", International Journal of Power Electronics and Drive Systems (IJPEDS), vol. 10, no. 4, pp. 2138-2147, 2019.

[20] B. Ghita, K. Mohammed, and L. Ahmed, "Application and comparison between the conventional methods and PSO method for maximum power point extraction in photovoltaic systems under partial shading conditions," ," International Journal of Power Electronics and Drive Systems (IJPEDS), vol. 9, no. 2, pp. 631-640, 2018.

[21] S. Li, "Optik A MPPT speed optimization strategy for photovolatic system using VWP interval based on weather forecast,” Opt. - Int. J. Light Electron Opt., vol. 192, no. June, p. 162958, 2019.

[22] U. Yilmaz, O. Turksoy, and A. Teke, "Electrical Power and Energy Systems Improved MPPT method to increase accuracy and speed in photovoltaic systems under variable atmospheric conditions," Electr. Power Energy Syst., vol. 113, no. June, pp. 634-651, 2019.

[23] S. Veerapen et al., "A novel global maximum power point tracking algorithm for photovoltaic system with variable perturbation frequency and zero oscillation," Sol. Energy, vol. 181, no. January, pp. 345-356, 2019.

[24] J. Ahmed and Z. Salam, "A Maximum Power Point Tracking (MPPT) for PV system using Cuckoo Search with partial shading capability," Appl. Energy, vol. 119, pp. 118-130, 2014.

[25] X. Yang and S. Deb, "Cuckoo Search via Levy Flights," in 2009 World Congress on Nature \& Biologically Inspired Computing (NaBIC), 2009, pp. 210-214.

\section{BIOGRAPHIES OF AUTHORS}
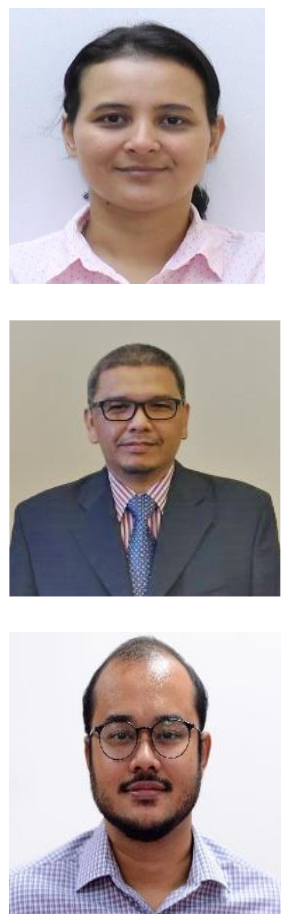

Chanuri Charin received the BEng (Hons) degree in electrical engineering from Universiti Teknologi Malaysia, Johor, Malaysia and the MSc in electrical and electronics engineering from Universiti Sains Malaysia, Penang, Malaysia in 2008 and 2013 respectively. She is currently pursuing $\mathrm{PhD}$ degree in the field of power electronics engineering at Universiti Sains Malaysia. She is also currently a lecturer at the Faculty of Engineering Technology, Universiti Malaysia Perlis, Perlis, Malaysia. Her current research interests include renewable energy and power electronic converters.

Dahaman Ishak received the BSc degree in electrical engineering from Syracuse University, Syracuse, NY, USA, the MSc degree in electrical power from University of Newcastle, Newcastle upon Tyne, $\mathrm{UK}$, and the $\mathrm{PhD}$ degree in electrical engineering from the University of Sheffield, Sheffield, UK, in 1990, 2001 and 2005 respectively. He is currently an Associate Professor with the School of Electrical and Electronic Engineering, Universiti Sains Malaysia. His current research interests include permanent magnet brushless machines, electrical drives, power electronic converters and renewable energy.

Muhammad Ammirrul Atiqi Mohd Zainuri received his B.Eng. in Electrical and Electronic Engineering and Master of science degree from the Universiti Putra Malaysia (UPM), Malaysia in 2011 and 2013, respectively. He then continued and received his Doctor of Philosophy degree in Electrical Power Engineering (major in Power Electronics and Power Quality) from UPM in 2017. Currently, he is a Senior Lecturer at Department of Electrical, Electronics and Systems Engineering, Universiti Kebangsaan Malaysia (UKM), Malaysia. His research interests include Power Electronics, Power Quality, Renewable Energy System, Energy Storage System, and Artificial Intelligent. He is also a research member at Advanced Lightning and Power Energy Research (ALPER) at UPM and UM Power Energy Dedicated Advanced Centre at UM. 